\title{
A Fuzzy-based Decision Support Tool for Engineering Curriculum Design
}

\author{
O. Bologa, R.E. Breaz, S.G. Racz
}

\author{
Octavian Bologa, Radu-Eugen Breaz*, \\ Gabriel Sever Racz \\ Lucian Blaga University of Sibiu \\ No.10, Victoriei, Sibiu, 550024, România, \\ octavian.bologa@ulbsibiu.ro, radu.breaz@ulbsibiu.ro, gabriel.racz@ulbsibiu.ro \\ *Corresponding author: radu.breaz@ulbsibiu.ro
}

\begin{abstract}
:
This paper describes a decision support tool which can be used for aiding the academic sraff in making the decision of including a specialty subject in an engineering curriculum. The approach is based on building a list of competences that should be acquired through the study of the specialty subjects. An evaluation of the competences is made by means of questionnaires and finally, a fuzzy model will be run. The output of the fuzzy model reflects the need for the evaluated specialty subject to be included in the curriculum. The proposed method takes into consideration the opinions and experience of both the academic staff and the employers.

Keywords: curriculum design, decision support engineering studies, fuzzy logic.
\end{abstract}

\section{Introduction}

National regulations state that engineering curriculum in the Romanian universities is composed mainly by four categories of subjects: fundamental subjects, domain subjects, specialty subjects and complementary subjects.

The fundamental subjects include Mathematics, Physics, Chemistry and other fundamental sciences which provide the future engineer the basic knowledge for operating with the laws and principles of engineering.

The domain subjects are intended to provide the technical knowledge related to a specific area of engineering, which at national level is called "domain". For example, some engineering domains in Romania are Mechanical Engineering, Industrial Engineering, Chemical Engineering, Electrical Engineering and many other.

The specialty subjects are intended to provide the specific knowledge which individualizes a study programme (also called "specialization") within and engineering domain. For example, Machine Building Technology and Machine-tools and Production Systems are two different specializations within the Industrial Engineering domain.

The complementary subjects are intended to provide the graduates the transversal competences and for engineering study programmes are usually selected from a list that include Foreign Language, History of Technics, Sports, Culture and Civilizations, Communication Techniques and so other.

The national authority responsible with quality assurance within higher education system in Romania, ARACIS (Romanian Agency of Quality Assurance in Higher Education) has established several rules regarding the distribution of fundamental, domain, specialty and complementary subjects within the curriculum. There are rules regarding the percentages of every subject category and there are also lists of subjects for every engineering domain from which the universities have to choose the subjects within the curriculum. However, while the lists of fundamental 
and domain disciplines are quite restrictive, for the specialty subjects, the constraints are more flexible and the list of possible "subject-candidates" /options is richer.

The broader range of options, which in fact may be considered beneficial, creates a set of problems and difficulties regarding the answer to the question: Which specialty subjects have/have not to be included in the curriculum? These problems have to be solved by each university, taking into consideration two aspects: the university autonomy, which encourage every school to customize its curriculum and the rapid evolution of the labor market, which have to be addressed by the universities by rapid adaptation of the curriculum.

The research presented in this paper was conducted in order to develop a tool for aiding the university staff in the decision process of designing the engineering curriculum with regards of the specialty subjects. The remaining part of this paper is as follows. In second section, a survey of the state of the art regarding various approaches regarding engineering curriculum design is presented. Third section is dedicated to building a competence list, considered necessary for an engineering graduate to possess. In the fourth section the flowchart of the proposed method is presented and the fifth section introduces the fuzzy model used for assessing the percent of introducing an evaluated subject in the curriculum. The last section is dedicated to the conclusion.

\section{Previous work}

Curriculum design for engineering studies should be oriented to final outcome of the higher education process, providing the labor market with a graduate able to fulfill the requirements of the employers [1]. The problem is that there is a certain conflict between education, which is seen as the main objective by the universities and professional training on the other hand, which is seen as mandatory requirement by the employers.

A literature survey shows that Competence-Based Learning $[3,4]$ is one of the concepts considered as base for higher education curriculum design in order to bridge the gap between education and professional training [2]. Competences are defined as a combination of skills and knowledge and it is considered that an individual's performance at work are hardly influenced by them [3]. Moreover, it is considered that competences comprises also entrepreneurial elements which are also needed by a higher education graduate $[4,5]$.

Consequently, university staff and other academic organizations involved in the curriculum design process have to define and select the required competences in order to define and structure a successful engineering study programme. In order to customize a specialization among other, within the same domain, it is very important to define the specific competences and to provide them by means of the specialty subjects, while keeping the curriculum as flexible as possible [6]. However, care has to be taken in order to avoid too much specialization or too much generalization [7].

Fuzzy logic was used quite often to build decision support tools related to educational process. Many works are related to applications of fuzzy logic in assessing the academic performance of the students [8-10]. The results obtained by using the method presented in [8] were compared to the values produced by statistical means. Another research, presented in [11], proposed a fuzzy logic approach to the assessment of student centered learning.

With the widespread of e-learning and web-based learning, special software products called Learning Management Systems (LMS) are used in order to provide the platform for learning environment. Fuzzy logic algorithms are reported to be used for the evaluation of LMS systems [12].

Competence-Based Learning had risen the problem of selection, analysis and evaluation the required competences for a higher education study programme. A literature survey revealed 
that fuzzy logic was used for this purpose, using a revised DACUM method (13). DACUM is the abbreviation for Developing A CurriculuUM and was invented by a group of scientists from New Start Company in Canada's Nova Scotia. By using fuzzy composite evaluation, the work presented in [13]developed a very effective method of analyzing technical competences for graduates of junior colleges.

An approach which uses both fuzzy logic and competence selection and analysis was presented in [14] and [15]. A particular fuzzy model for assisting the decision of including a specialty subject in the curriculum, for a specialization within Industrial Engineering domain. The approach was developed by a team from "Lucian Blaga" University of Sibiu, which includes the authors of the present paper.

\section{The list of competences}

The approach proposed in this work is intended to have high degree of generality, in order to be applied practically to any engineering study programme which can be related to an industrial process. For example, the method can be applied for machine-building and manufacturing engineers, hydraulic and pneumatic machines engineers, welding engineers, textile and leather engineers, chemical engineers, electrical engineers and many other engineering fields.

It is considered that in order to become a specialist in any of the above mentioned branch of engineering, the specialty subjects have to provide the student knowledge in five major components: technology, equipment, automation and control systems, CAD/CAE/CAM (computer aided design/engineering/manufacturing) and research and development, as shown in figure 1 .

Consequently, a generalized list of competences which should be provided by the study of specialty subjects within the curriculum was built and presented below.

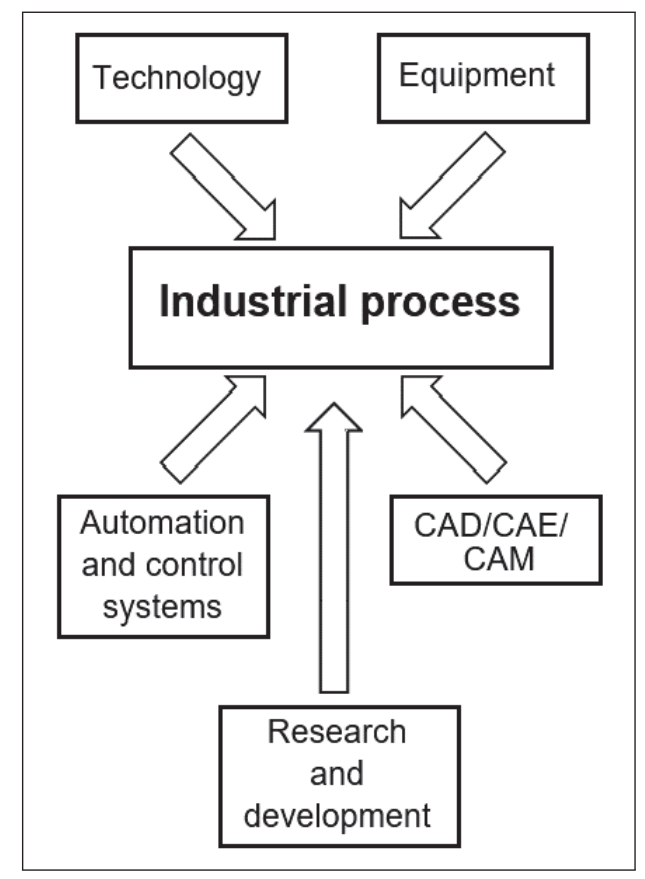

Figure 1: Major components of an industrial process

Competences related to TECHNOLOGY are grouped as follows:

- Competence to understand the basic principles of the technology (T1) 
- Competence to implement the technology and to assembly the logistic chain for its implementation (T2)

- Competence to design the technology (T3)

- Competence to troubleshoot and optimize the technology (T4)

Competences related to EQUIPMENT are grouped as follows:

- Competence to understand the structure and operation principles of the

equipment (E1)

- Competence to operate and maintain the equipment (E2)

- Competence to design the equipment (E3)

- Competence to troubleshoot and optimize the equipment (E4)

Competences related to AUTOMATION AND CONTROL SYSTEMS are grouped as follows:

- Competence to understand and apply the basic principles of automation and control systems for the process (A1)

- Competence to identify the components of the process which are suited for automation (A2)

- Competence to design, operate and maintain automation systems for the process (A3)

- Competence to troubleshoot and optimize automation systems for the process (A4)

Competences related to $C A D / C A E / C A M$ are grouped as follows:

- Competence to operate with $\mathrm{CAD} / \mathrm{CAE} / \mathrm{CAM}$ software developed for the process (C1)

- Competence to build 3D models of single parts and assemblies within the structure of the process components (technology, equipment, automation systems) (C2)

- Competence to realize mathematical models and to simulate the behavior of the process components (C3) - Competence to manufacture process components by means of computer automated machining $(\mathrm{C} 4)$

- Competence to use methods and software for optimizing the process components (C5)

Competences related to RESEARCH AND DEVELOPMENT are grouped as follows:

- Competence to investigate and analyze new processes, technologies, equipment and automation and control systems (R1)

- Competence to perform fundamental research for the process (R2)

- Competence to build experimental layouts for applicative researches for the process (R3)

- Competence to produce and test prototype products for the process (R4)

- Competence to write technical reports about the process (R5)

In order to exemplify the high degree of generality, for every competences from the list the generalized item was italicized. It can be easily noticed that the italicized words can be replaced with more specific items, related to a specialty subject form the curriculum of an engineering specialization. For example, taking into consideration machine-building engineering as specialization and "Plastic deformation technologies and equipment" as specialty subject, the italicized items could be replaced by specific items as follows:

- technology $\rightarrow$ plastic deformation technology

- equipment $\rightarrow$ plastic deformation equipment

- process $\rightarrow$ plastic deformation process.

\section{The flowchart of the proposed method}

The flowchart of the proposed method is presented in figure 2 .

The preliminary stage consists of two steps: developing a generalized set of competences and building a portfolio of specialty subjects.

The final stage consist of four steps. The first one involves the customization of the generalized set of competences for every evaluated subject, according to the specific requirements and characteristics of the study programme. As stated in the previous section, due to the high degree 


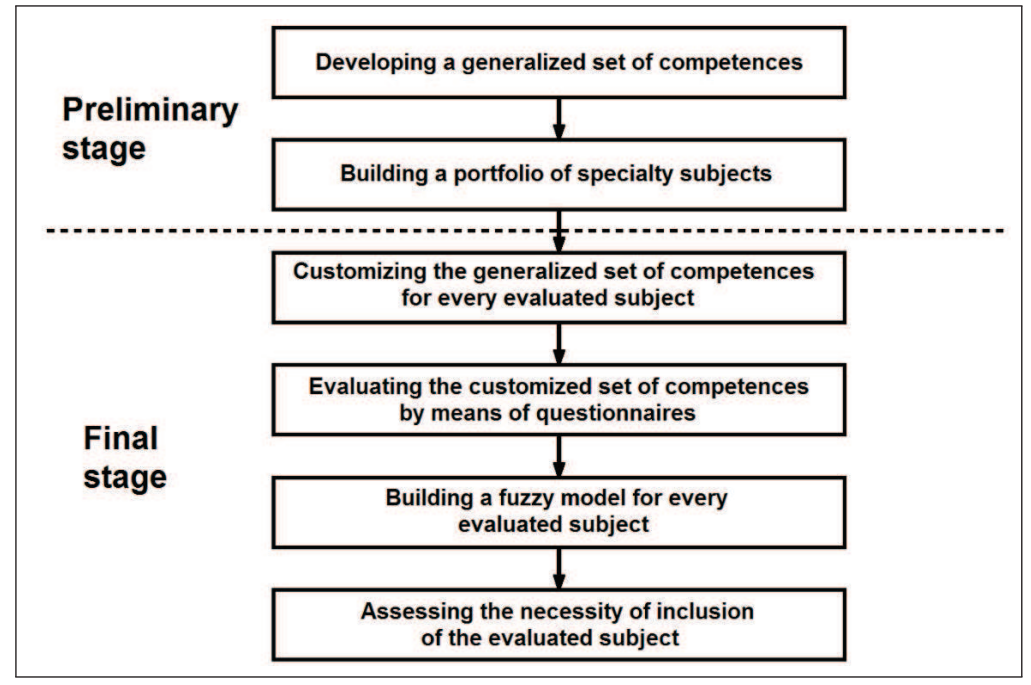

Figure 2: The flowchart of the proposed method

of generality of the generalized set of competences, the customization process is quite straightforward. The second step involves the evaluation of the customized set of competences by means of questionnaires. Because the method itself, the set of generalized and customized competences and the portfolio of specialty subjects are developed by the academic staff, the questionnaires are distributed to the other main stakeholders of the educational process, the employers.

The questionnaire (one for each evaluated subject) includes the set of customized competences, and asks the employers to grade each competence within the list with a grade from 1 to 10.

The next step involves the construction of a fuzzy model, also for every evaluated subject, which takes into consideration the results of the questionnaires for fuzzyfing the inputs.

Finally, after running the fuzzy model, the necessity of including the evaluated subject will be assessed.

\section{The fuzzy model}

The general structure of the fuzzy model is presented in figure 3. The inputs are the competences from the list presented in section 3.

For a certain specialty subject, the generalized fuzzy model has to be customized, by customizing the set of competences. Moreover, if the evaluated subject does not include one of the five categories of competences (for example a specialty subject with does not include technologyrelated chapters), that category can be removed from the inputs. Of course, for an engineering specialty subject it is hard to encounter such a situation, but nevertheless, it could appear.

The output variable of the fuzzy model is the "percentage of inclusion of the discipline (PI)" and will fluctuate as a percentage between 0 and $100 \%$. Only the disciplines which obtain a percentage of inclusion equal or greater than a threshold (for example $80 \%$ ) will be considered to be included in the curricula.

The linguistic variables used for the fuzzification of the inputs T1, T2, E1, E2, A1, A2, C1, C2, C3 and C4 were chosen as:useless;necessary; mandatory.

The linguistic variables used for the fuzzification of the inputs T3, T4, E3, E4, A3, A4, C5, R1, R2, R3, R4 and R5 were chosen as: inefficient; efficient.

The linguistic variables for the output were chosen as: low; medium; high. 
The fuzzyfication of the inputs was done by using the membership functions presented in figure 4 ( for T1, T2, E1, E2, A1, A2, C1, C2, C3 and C4) and figure 5 (for T3, T4, E3, E4, A3, $\mathrm{A} 4, \mathrm{C} 5, \mathrm{R} 1, \mathrm{R} 2, \mathrm{R} 3, \mathrm{R} 4$ and R5).

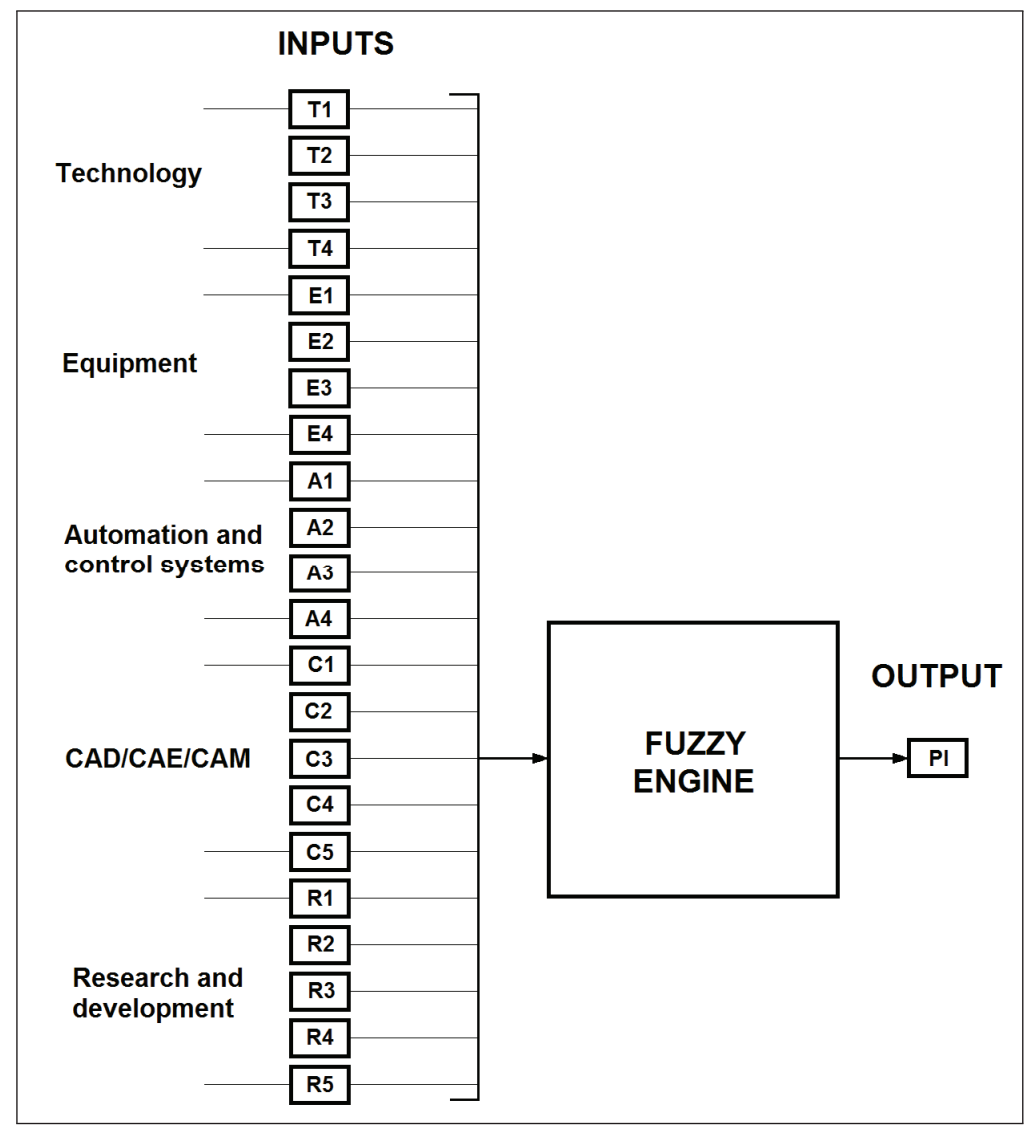

Figure 3: The structure for a fuzzy model

The membership function used for the fuzzification of the output is shown in figure 6 .

The membership functions from figures 3-5 were built using only triangular and trapezoidal curves. The triangular curve is a function of a vector $\mathrm{x}$ and depends on three scalar parameters $\mathrm{a}, \mathrm{b}$ and $\mathrm{c}$ as given by:

$$
f(x, a, b, c)=\left\{\begin{array}{cc}
0, & x \leq a \\
\frac{x-a}{b-a}, & a \leq x \leq b \\
\frac{c-x}{c-b}, & b \leq x \leq c \\
0, & c \leq x
\end{array}\right.
$$




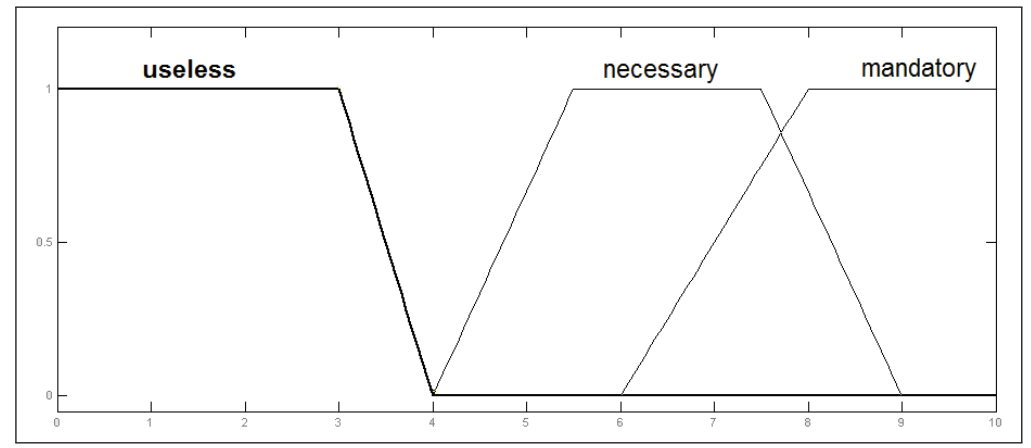

Figure 4: The membership function for fuzzyfication of the inputs T1, T2, E1, E2, A1, A2, C1, $\mathrm{C} 2, \mathrm{C} 3$ and $\mathrm{C} 4$

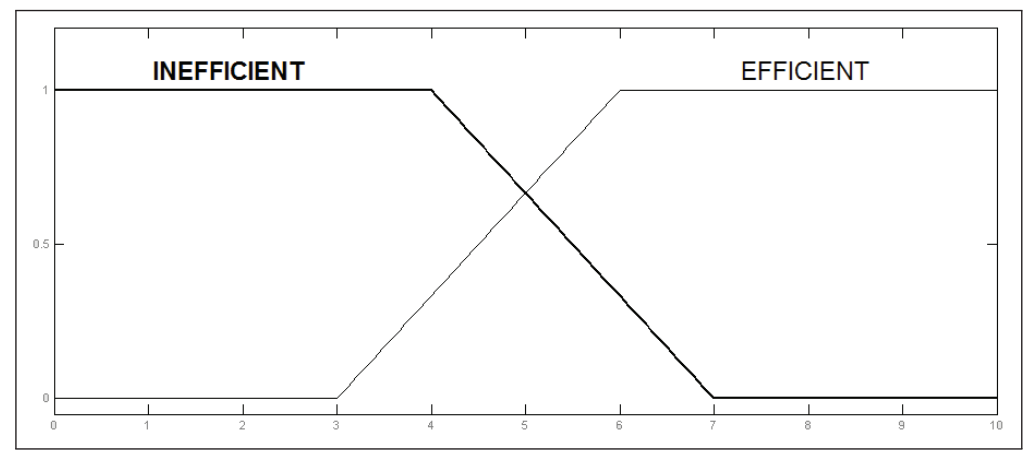

Figure 5: The membership function for fuzzyfication of the inputs T3, T4, E3, E4, A3, A4, C5, $\mathrm{R} 1, \mathrm{R} 2, \mathrm{R} 3, \mathrm{R} 4$ and $\mathrm{R} 5$

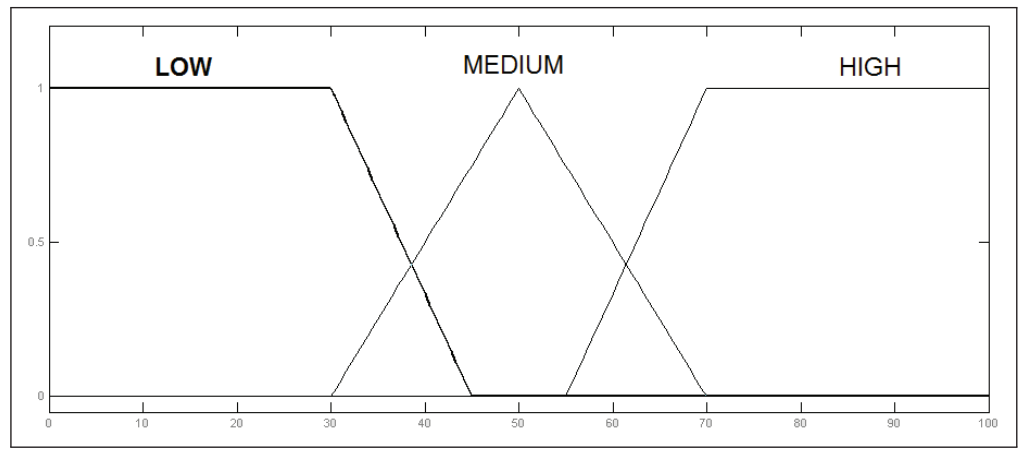

Figure 6: The membership function for fuzzyfication of the output 
The trapezoidal curve is a function of a vector $\mathrm{x}$ and depends on four scalar parameters $\mathrm{a}, \mathrm{b}$, $c$ and $d$ as given by:

$$
f(x, a, b, c, d)=\left\{\begin{array}{cc}
0, & x \leq 0 \\
\frac{x-a}{b-a}, & a \leq x \leq b \\
1, & b \leq x \leq c \\
\frac{d-x}{d-c}, & c \leq x \leq d \\
0, & d \leq x
\end{array}\right.
$$

As development tool, the Matlab (with Fuzzy Logic Tcoolbox) was used. The other characteristics of the fuzzy model are: AND method minimum; OR method maximum; Implication method minimum; Aggregation method maximum; Defuzzification method centroid (center of gravity).

\section{Conclusion}

The main goal of this research was to develop a decision support tool, based on fuzzy logic for the decision of including or eliminating a specialty discipline within an engineering curriculum.

The proposed tool will help the academic staff to choose from a portfolio of specialty subjects. Usually, this portfolio is imposed by the national authorities for higher education in each country. Of course, the number of disciplines within the portfolio is higher as the number of disciplines which can be included in the curriculum, so the universities have to choose between them, a process which is often extremely difficult.

A list of competences which a future graduate of a four years engineering programme (seen as an industrial processes engineer) should possess after studying the subjects form above-mentioned portfolio was built. The competences within the list were divided into technology related, equipment related, automation and control systems related, $\mathrm{CAD} / \mathrm{CAM} / \mathrm{CAE}$ related and research and development related.

The list of competences were distributed (as questionnaires) to industrial companies in order to be assessed. The staff of companies, which are the main employer of the engineering graduates were asked to grade every competence from the list with grades between 1 and 10 . Using the list of competences and the grades, fuzzy models were built for each subject within the portfolio. The inputs of each fuzzy model were the set of customized competences selected from the list and the output was the percent of inclusion in the curriculum. The fuzzyfication of the inputs was made according to a chosen set of membership functions and to the grades received by each competence.

Finally, the models were used to assist the decision of including the discipline in the curricula by allowing the user to calculate the percent of inclusion.

\section{Bibliography}

[1] National Science Foundation (1996), Shaping the future: New expectations for undergraduate education in science, mathematics, engineering and technology, Report NSF 96-139, Washington DC.

[2] Ellstrom P. (1997), The many meaning of occupational competence and qualification, Journal of European Industrial Training, 21(6): 266-273. 
[3] Sanchez J.(2010), University training for competency of sustainability practitioner. Its impact on intention of creation, Springer Science + Bussines Media.

[4] Sanchez J. (2010), University training for entrepreneurial competences. Its impact on intention of venture creation, International Entrepreneurship and Management Journal, 7: 239-254.

[5] Nab J. et al. (2010), Authentic competence-based learning in university education in entrepreneurship, International Journal of Entrepreneurship and Small Business, 9(11):20-35.

[6] Pearce H.T. (1997), Flexibility in the engineering curriculum: a vital component for the Future, Proc. of the National Seminar on Engineering Education, South Africa, University of Cape Town, 27-28 September 1997, 198-206.

[7] Mulder M. et al. (20009), The new competence concept in higher education: error or enrichment, Journal of European Industrial Training, 33(8/9): 755-770.

[8] Khairul A., Qiang S. (2006), Data-Driven Fuzzy Rule Generation and its Application for Student Academic Performance Evaluation, Journal of Applied Intelligence, 25: 305-319.

[9] Bai S.M., Chen S.M. (2008); Evaluating students' learning achievement using fuzzy membership functions and fuzzy rules, IEEE Expert Systems with Applications, 34(1): 399-410.

[10] Chen S.M., Lee C.H. (1999), New methods for students' evaluating using fuzzy sets, Fuzzy Sets and systems, 104(2): 209-218.

[11] Ma J., Zhou D. (2000), Fuzzy set approach to the assessment of student-centered learning, IEEE Transaction on Education, 2:237-241.

[12] Cavus N. (2010), The evaluation of Learning Management systems using an artificial intelligence fuzzy logic algorithm, Advances in Engineering Software, 41:248-254.

[13] Chang L.T., Hong C.M., Shih C.H. (1996); An Application of Fuzzy Theory to Technical Competency Analysis for the Entry-Level Electronic Technician, Intl. Fuzzy Systems and Intelligent Control Conference, Louisville KY, USA, April 8-10, 1-11.

[14] Bologa O., Beck W., Schupp P., Breaz R., Racz G., Ionescu F. (2009); A decision algorithm for optimizing the specialty curricula in machine tools and production systems engineering studies, 5th Balkan Region Conference on Engineering and Business Education \& 2nd International Conference on Engineering and Business Education, Sibiu, Romania, 15 - 17 October, 330-335.

[15] Beck W., Schupp P., Bologa O., Breaz R., Racz G., Ionescu F. (2010); Mathematical Model for Aiding the Decision of Changing the Curriculum for Higher Education in the Industrial Engineering Domain, ICERI 2010 Intl. Conf. of Education, Research and Innovation, 15-17 November, Madrid, Spain, 6535-6542. 